\title{
TESTE DE CONDUTIVIDADE ELÉTRICA EM FUNÇÃO DO PERÍODO E DA TEMPERATURA DE EMBEBIÇÃO PARA SEMENTES DE MILHETO ${ }^{1}$
}

\author{
CAROLINA MARIA GASPAR², JOÃO NAKAGAWA ${ }^{3}$
}

\begin{abstract}
RESUMO - O presente trabalho objetivou estudar os efeitos de período e temperatura de embebição sobre os resultados do teste de condutividade elétrica para a avaliação do vigor de sementes de milheto (Pennisetum americanum L.). Foram realizados dois experimentos. No primeiro, estudaram-se os períodos de embebição de 2, 4, 6, 8, 10, 12, 14, 16, 18, 20, 22 e 24 horas, à temperatura de $25^{\circ} \mathrm{C}$, e no segundo as temperaturas de $20,25,30,35$ e $40^{\circ} \mathrm{C}$, em período de embebição mais promissor do primeiro experimento. Os testes foram realizados com três lotes de sementes, sendo o lote 1 representado pela cultivar Comum e os lotes 2 e 3 pela cultivar BN2, utilizando-se para cada repetição 100 sementes em $100 \mathrm{ml}$ de água para embebição. Empregou-se delineamento experimental inteiramente casualizado, com quatro repetições por tratamento. Os resultados mostram que é possível reduzir o período de embebição das sementes para duas horas e que nesse período a temperatura teve pouca influência. Assim sendo, a temperatura de $25^{\circ} \mathrm{C}$, durante a embebição, parece a mais conveniente para a condução deste teste.
\end{abstract}

Termos para indexação: milheto, Pennisetum americanum, sementes, condutividade, testes de vigor.

\section{ELECTRICAL CONDUCTIVITY TEST IN FUNCTION OF THE PERIOD AND THE TEMPERATURE OF IMBIBITION SOLUTION FOR SEEDS OF PEARL MILLET}

\begin{abstract}
Two experiments were carried out [with the purpose of studying] to study the effects of imbibition period and temperature of imbibition on the results of the electrical conductivity test for the evaluation the vigor of pearl millet to evaluate pearl millet (Pennisetum americanum $L$.) seeds vigor. In the first experiment was studied the imbibition periods of $2,4,6,8,10,12,14$, $16,18,20,22$ and 24 hours, [to the temperature of] at $25^{\circ} \mathrm{C}$ were studied, and in the second at the temperatures of $20,25,30,35$ and $40^{\circ} \mathrm{C}$, (in a more promising imbibition period more promising of than the first experiment.????) AD Three seeds lots were compared, lot 1 represented by $\mathrm{cv}$. Comum and the lots 2 and 3 by cv. BN2. Four replicates of 100 seeds in $100 \mathrm{ml}$ of imbibition water were employed for all the treatments. The experimental design was the complete entirely randomized block, with four replications for all the treatments. Results indicated that the period of imbibition period can be reduced to two hours and that in this period the temperature had little influence on the results. As such, $25^{\circ} \mathrm{C}$ seems a convenient imbibition temperature for the conduction of this test.
\end{abstract}

Index terms: pearl millet, seeds, electrical conductivity test, vigour tests, Pennisetum

\footnotetext{
${ }^{1}$ Aceito para publicação em 06.12.2002.

${ }^{2}$ Graduanda em Eng ${ }^{\mathrm{a}}$ Agronômica, Depto. de Produção Vegetal - FCA/ UNESP; Cx. Postal 237, 18603-970, Botucatu-SP, Brasil; bolsista da FAPESP; tel: 68027172; e-mail: carolmgaspar@ig.com.br

${ }^{3}$ Eng $^{\circ} \mathrm{Agr}^{\circ}$, Prof. Titular Aposentado, Depto. de Produção Vegetal - FCA/ UNESP, Cx. Postal 237, 18603-970, Botucatu-SP, Brasil; bolsista do CNPQ; tel: 68027172; e-mail: secdamv@fca.unesp.br
}

\section{INTRODUÇÃO}

O milheto (Pennisetum americanum (L.)) Leeke pode ser utilizado para a produção de palha e cobertura do solo no sistema de semeadura direta e para alimentação animal, como forrageira anual de verão em pastejo direto, para corte, silagem e colheita dos grãos para rações (Salton \& Kichel, 1997). A qualidade da semente é um fator preponderante para o sucesso de qualquer cultura. Por essa razão, vários testes tem sido 
utilizados para avaliar a qualidade das sementes de milheto. Dentre os testes de vigor considerados mais importantes pela International Seed Testing Association (Hampton \& Tekrony, 1995), pode-se destacar o teste de condutividade elétrica como um dos mais indicados para estimar o vigor, devido a sua objetividade e rapidez, além da facilidade de execução na maioria dos laboratórios de análise de sementes, sem maiores despesas em equipamento e treinamento de pessoal (Vieira \& Krzyzanowski, 1999). Este teste preenche ainda os requisitos básicos de um teste de vigor eficiente (Matthews \& Powell, citados por Marcos Filho et al., 1990).

O teste de condutividade elétrica baseia-se no fato de que o vigor está relacionado à integridade do sistema de membranas celulares e desta forma avalia indiretamente o estado de degeneração das membranas (Marcos Filho et al., 1987; Vieira \& Krzyzanowski, 1999). Os resultados deste teste podem ser afetados por vários fatores, como: qualidade da água, temperatura, duração do período de embebição, grau de umidade e número de sementes testadas (Dias \& Marcos Filho, 1995; Vanzolini, 1998; Vieira \& Krzyzanowski, 1999), além do genótipo (Vieira et al., 1996).

Neste teste a duração do período de embebição das sementes tem também grande efeito sobre a capacidade do teste de distinguir diferenças de qualidade entre os lotes (Dias \& Marcos Filho, 1995). O período que se recomenda é de 24 horas de embebição (Marcos Filho et al., 1987; Hampton \& Tekrony, 1995; Vieira e Krzyzanowsky, 1999), porém, a possibilidade da redução deste período é vantajosa para a indústria de sementes. Resultados que avaliem a qualidade fisiológica das sementes rapidamente encurtam o período de tomada de decisão da indústria de sementes (Marcos Filho et al., 1990; Dias \& Marcos Filho, 1995).

Marcos Filho et al. (1990) e Dias \& Marcos Filho (1995) obtiveram distinção entre lotes de sementes de soja, quando a diferença de vigor era grande, com o uso de 4 ou 8 horas de embebição; entretanto, quando a diferença entre os lotes era pequena, o período de embebição por 16 ou 20 horas mostrou-se mais sensível às variações do vigor das sementes de soja. Já para girassol, Brandão Jr. et al. (1997) conseguiram detectar as diferenças de qualidade existentes entre os lotes com 18 horas de embebição. Ainda, Vanzolini \& Nakagawa (1999b), realizando trabalho com amendoim, observaram que o tempo de embebição de 3 horas foi suficiente para distinguir a qualidade de diferentes lotes de sementes. Dias et al. (1998), conduzindo testes de condutividade elétrica com feijão-de-vagem e quiabo, verificaram para o feijão-devagem um aumento progressivo das leituras com o decorrer do período de embebição. Observaram ainda que, somente nas leituras de condutividade elétrica feitas a partir de 20 horas, foi possível a identificação do lote mais vigoroso. Para o quiabo, com quatro horas de embebição foi possível detectar diferenças entre os lotes e apontar o lote de melhor qualidade fisiológica. Para as duas espécies estudadas, informações mais precisas sobre o vigor dos lotes foram obtidas com 24 horas de embebição. Rodo et al. (1998) constataram ser viável reduzir o tempo de embebição para sementes de tomate de 24 para 4 horas, enquanto Sá (1999), trabalhando com outras cultivares de tomate, observou a possibilidade de redução do período para 6 horas. Ribeiro et al. (1997) verificaram para milho que com o período de 12 horas foi possível detectar diferenças na qualidade fisiológica dos lotes de sementes.

Quanto à temperatura de embebição, sua influência é verificada na velocidade de embebição e de lixiviação de eletrólitos do interior das células para o meio externo (Leopold, 1980). Loeffler (1981) constatou que a diminuição na temperatura causa aumento na viscosidade da solução, seguida por um decréscimo na mobilidade de íons e conseqüente redução da condutividade; em contrapartida, as altas temperaturas aumentam a dissociação de íons e reduzem a viscosidade da solução, o que resulta em alta condutividade.

Vanzolini \& Nakagawa (1999a) realizaram o teste de condutividade elétrica para sementes de amendoim com três horas de embebição e observaram que, à temperatura de $40^{\circ} \mathrm{C}$, houve a possibilidade de separação dos três lotes quanto à qualidade; e ainda que a elevação da temperatura propiciou aumentos significativos nos valores de condu-tividade. Também, Rodo et al. (1998) concluíram que o teste de condu-tividade elétrica conduzido à temperatura de $25^{\circ} \mathrm{C}$ apresentou maior eficiência de separação de lotes de sementes de tomate, para as duas cultivares estudadas, em relação a $20^{\circ} \mathrm{C}$.

O objetivo do presente trabalho foi estudar, em sementes de milheto, o efeito do período e da temperatura de embebição, nos valores de condutividade elétrica da solução de embebição.

\section{MATERIAIS E MÉTODOS}

O trabalho, que constitui-se de dois experimentos, foi conduzido no Laboratório de Análise de Sementes do Departamento de Produção Vegetal - Setor Agricultura da Faculdade de Ciências Agronômicas, da Universidade Estadual Paulista 
(UNESP), em Botucatu - SP. Foram utilizados três lotes de sementes de milheto, sendo o lote $1, \mathrm{cv}$ Comum, proveniente da safra 1999/2000, o lote 2, cv. BN2, proveniente da safra 1998/1999 e o lote 3, cv. BN2, proveniente da safra 1999/2000; de cada lote foi retirada uma amostra de um quilograma de sementes para a realização dos estudos.

As sementes de milheto, para os três lotes, foram classificadas por peneiras de malha quadrada, sendo: peneira 1 $\geq 2,00 \mathrm{~mm}$, peneira $2<2,00 \mathrm{~mm}$ a $\geq 1,68 \mathrm{~mm}$, peneira $3<$ $1,68 \mathrm{~mm}$ a $\geq 1,41 \mathrm{~mm}$, peneira $4<1,41 \mathrm{~mm} \mathrm{a} \geq 0,71 \mathrm{~mm} \mathrm{e}$ fundo $<0,71 \mathrm{~mm}$. A quantidade retida foi pesada e depois calculada a porcentagem de retenção de cada peneira. As sementes com diâmetro menor que $1,41 \mathrm{~mm}$ foram eliminadas para a obtenção de lotes mais uniformes quanto ao tamanho (Gaspar \& Nakagawa, 2001). Após a uniformização dos lotes, as avaliações das sementes foram realizadas.

Foram avaliados para as sementes: peso de $\mathbf{1 0 0 0}$ sementes, baseando-se nas Regras para Análise de Sementes (Brasil, 1992); teor de água das sementes, pelo método da estufa a $105 \pm 3^{\circ} \mathrm{C}$ por $24 \mathrm{~h}$ (Brasil, 1992); germinação, realizado sob alternância de temperatura de $20-30^{\circ} \mathrm{C}$, em papel toalha (RP), umedecido com água destilada na proporção de duas vezes o peso do papel seco, com quatro repetições de 100 sementes por lote, seguindo-se os procedimentos das Regras para Análise de Sementes (Brasil, 1992); primeira contagem do teste de germinação foi considerada como teste de vigor, e avaliada no terceiro dia após a semeadura; condutividade elétrica, realizada com quatro repetições de 50 sementes, sendo estas inteiras e sem as glumas, pesadas e colocadas em copos plásticos descartáveis, com capacidade de $200 \mathrm{ml}$; adicionaram-se $75 \mathrm{ml}$ de água destilada e foram mantidos por 24 horas em câmara a $25^{\circ} \mathrm{C}$. Após este período, determinou-se a condutividade da solução na qual encontravam-se imersas as sementes e os resultados calculados em $\mu \mathrm{S} \mathrm{cm}^{-1} \mathrm{~g}^{-1}$ (Vieira \& Krzyzanowski, 1999); envelhecimento acelerado, empregouse gerbox modificado com 40ml de água destilada (Marcos Filho et al., 1987), mantido em câmara a $41^{\circ} \mathrm{C}$ por 48 horas (Garcia \& Menezes, 1999), para a seguir serem submetidas ao teste de germinação (Brasil, 1992), utilizando-se quatro repetições de 100 sementes por lote; emergência de plântulas, realizada com quatro repetições de 100 sementes, semeadas em solos contidos em bandejas plásticas mantidas em túnel plástico pelo período do teste. Avaliou-se diariamente o número de plântulas emergidas, até a estabilização da emergência (10 dias). Foram consideradas a porcentagem de emergência e a velocidade, calculada pelo índice de velocidade de emergência (IVE) (Maguire, 1962).
No primeiro experimento (E1) variou-se o período de embebição para o teste de condutividade elétrica. Utilizaramse 100 sementes e $100 \mathrm{ml}$ de água destilada, para as quatro repetições, e para cada tempo de embebição, que foram: 2, $4,6,8,10,12,14,16,18,20,22$ e 24 horas, empregando-se os três lotes de sementes. As amostras foram pesadas e colocadas em copos plásticos descartáveis, com capacidade de $200 \mathrm{ml}$ e foram mantidas em câmara a $25^{\circ} \mathrm{C}$. Após a leitura da condutividade, as sementes foram separadas da solução e o excesso de água das sementes retirada com papel toalha antes de se determinar o teor de água (embebição), pelo método da estufa a $105 \pm 3^{\circ} \mathrm{C}$ por $24 \mathrm{~h}$ (Brasil, 1992).

No segundo experimento (E2), foi estudada a temperatura para a avaliação da condutividade elétrica da solução, de forma a tentar adequar a melhor temperatura ao melhor período de embebição. Utilizaram-se quatro repetições de 100 sementes e $100 \mathrm{ml}$ de água destilada, as quais foram mantidas por período considerado o mais promissor de acordo com os resultados obtidos no experimento 1, em câmaras a temperaturas de 20 , $25,30,35$ e $40^{\circ} \mathrm{C}$, empregando-se os três lotes de sementes. As amostras foram pesadas e colocadas em copos plásticos descartáveis, com capacidade de $200 \mathrm{ml}$. Com essa metodologia foram feitos dois testes; no primeiro não houve o controle da temperatura inicial da água (E2C1), ou seja, empregou-se água a temperatura ambiente; já no segundo, a temperatura inicial da água utilizada no teste foi controlada de forma a estar na mesma temperatura que a câmara (E2C2), de acordo com a recomendação encontrada em Vieira \& Krzyzanowski (1999). Após a leitura da condutividade, as sementes foram separadas da solução e o excesso de água das sementes retirada com papel toalha para que fosse determinado o teor de água (embebição), pelo método da estufa a $105 \pm 3^{\circ} \mathrm{C}$ por $24 \mathrm{~h}$ (Brasil, 1992).

Procedimento Estatístico: O delineamento experimental empregado em todos os testes foi o inteiramente casualizado. $\mathrm{Na}$ análise estatística dos dados, para caracterização dos lotes, consideraram-se 3 lotes e 4 repetições; para o experimento 1 , utilizou-se fatorial, lotes $\mathrm{x}$ horas de embebição $(3 \times 12)$ e no experimento 2 (E2C1 e E2C2) o fatorial lotes $\mathrm{x}$ temperatura de embebição $(3 \times 5)$. Para o teor de água em função de diferentes períodos de embe-bição (Experimento 1), utilizou-se análise de regressão. As médias foram comparadas pelo teste de Tukey e os dados em porcentagem transformados em arcsen $(\mathrm{x} / 100)^{1 / 2}$ (Pimentel - Gomes, 1973). As médias das tabelas são dos dados originais. 


\section{RESULTADOS E DISCUSSÃO}

\section{Caracterização dos Lotes}

A porcentagem de retenção nas peneiras 1, 2, 3, 4 e fundo para os lotes de semente de milheto demonstrou que todos os lotes tinham maior porcentagem de sementes retidas na peneira 2. Analisando-se a Tabela 1, observa-se que, em geral, o lote 2 apresentou maior proporção de sementes graúdas, enquanto o lote 3 maior quantidade de sementes miúdas e o lote 1 valores intermediários, justificando os pesos de 1000 sementes obtidos para esses lotes (Tabela 1).

O teor de água (Tabela 1) dos lotes apresentouse em torno de $10 \%$, ou seja, dentro da faixa que não influenciaria no teste de condutividade, de acordo com Vieira \& Krzyzanowski (1999). Apesar de haver diferença estatística do teor entre os lotes, pode-se considerá-los semelhantes, pois as diferenças foram pequenas $\mathrm{e}$, portanto, não devem ter interferido nas avaliações.

O lote 1 mostrou ser o mais vigoroso (Tabela 1), pois apresentou melhores resultados para germinação e vigor, pelos testes de $1^{\text {a }}$ contagem do teste de germinação e condutividade elétrica; pelo teste de emergência de plântulas e índice de velocidade de emergência apresentou comportamento semelhante aos lotes $2 \mathrm{e}$ 3. Germinação inferior foi exibida pelo lote 3 , embora sem diferir estatisticamente do lote 2. Pelos testes de vigor, o lote 3 foi inferior para a $1^{\mathrm{a}}$ contagem do teste de germinação, emergência de plântulas e índice de velocidade de emergência, enquanto o lote 2 apresentou-se menos vigoroso pelo teste de condutividade elétrica. Pelo teste de envelhecimento acelerado (Tabela 1) não houve diferença estatística entre os lotes. Essa diferença de discriminação entre os lotes, pode ser em função dos testes empregados na caracterização avaliarem atributos ou estádios diferentes de deterioração das sementes.

\section{Experimento 1 (E1)}

Não houve interação entre os períodos de embebição e os lotes, sendo assim, para os resultados de condutividade elétrica (Tabela 2) em todos os períodos de embebição foi possível a separação dos lotes quanto ao vigor, demonstrando que qualquer um dos períodos estudados possibilitou a diferenciação dos lotes.

O lote 1 mostrou-se de melhor vigor seguido pelo lote $3 \mathrm{e}$, por último, o lote 2 (Tabela 2). Estes resultados assemelham-se com os apresentados na Tabela 1, onde
TABELA 1. Caracterização dos três lotes de sementes de milheto (dados médios) quanto ao peso de 1000 sementes (g), teor de água $(\%), 1^{a}$ contagem do teste de germinação $(\%)$, germinação $(\%)$, envelhecimento acelerado $(\%)$, condutividade elétrica $\left(\mu \mathrm{S} \mathrm{cm} \mathrm{cm}^{-1} \mathrm{~g}^{-1}\right)$, emergência de plântulas (\%), índice de velocidade de emergência (IVE) e porcentagem de retenção em peneiras 1, 2, 3, 4 e fundo.

\begin{tabular}{|c|c|c|c|c|}
\hline \multirow{2}{*}{ Característica } & \multicolumn{3}{|c|}{ Lotes } & \multirow{2}{*}{ CV $(\%)$} \\
\hline & 1 & 2 & 3 & \\
\hline$\%$ Peneira $1^{1}$ & 12,37 & 26,27 & 5,92 & - \\
\hline$\%$ Peneira $2^{1}$ & 63,40 & 40,98 & 52,16 & - \\
\hline$\%$ Peneira $3^{1}$ & 21,82 & 27,31 & 38,61 & - \\
\hline$\%$ Peneira $4^{1}$ & 0,95 & 4,61 & 3,06 & - \\
\hline Fundo ${ }^{(1)}$ & 1,46 & 0,83 & 0,25 & - \\
\hline Peso de 1000 & $6,15 \mathrm{~B}^{2}$ & $6,87 \mathrm{~A}$ & $5,27 \mathrm{C}$ & 3,12 \\
\hline Teor de água & $10,20 \mathrm{~A}$ & $9,80 \mathrm{C}$ & $10,00 \mathrm{~B}$ & 0,14 \\
\hline $1^{\mathrm{a}}$ Contagem & $81,00 \mathrm{~A}$ & $54,00 \mathrm{AB}$ & $42,00 \mathrm{~B}$ & 21,89 \\
\hline Germinação & $82,00 \mathrm{~A}$ & $66,00 \mathrm{AB}$ & $57,00 \mathrm{~B}$ & 12,83 \\
\hline Envelhecimento & $42,00 \mathrm{~A}$ & $42,00 \mathrm{~A}$ & $33,00 \mathrm{~A}$ & 13,60 \\
\hline Condutividade & $60,12 \mathrm{~B}$ & $80,11 \mathrm{~A}$ & $68,45 \mathrm{AB}$ & 10,67 \\
\hline Emergência & $59,00 \mathrm{AB}$ & $68,00 \mathrm{~A}$ & $47,00 \mathrm{~B}$ & 8,11 \\
\hline IVE & $6,17 \mathrm{AB}$ & 7,94 A & $5,08 \mathrm{~B}$ & 18,24 \\
\hline
\end{tabular}

\footnotetext{
${ }^{1}$ Sem análise estatística.

${ }^{2}$ Médias seguidas da mesma letra na linha não diferem significamente ao nível de $5 \%$ de probabilidade pelo teste de Tukey.
}

TABELA 2. Dados médios de condutividade elétrica $\left(\mu \mathrm{S} \mathrm{cm}^{-1} \mathrm{~g}^{-1}\right)$, em função de diferentes períodos de embebição, para três lotes de sementes de milheto.

\begin{tabular}{ccccc}
\hline \multirow{2}{*}{$\begin{array}{c}\text { Horas de } \\
\text { embebição }\end{array}$} & 1 & 2 & 3 & Média \\
\cline { 2 - 4 } 2 & 15,10 & 24,01 & 23,70 & $20,94 \mathrm{~g}^{1}$ \\
4 & 23,78 & 33,36 & 28,21 & $28,45 \mathrm{f}$ \\
6 & 26,57 & 35,60 & 32,99 & $36,63 \mathrm{e}$ \\
8 & 32,48 & 39,94 & 41,37 & $37,92 \mathrm{e}$ \\
10 & 36,32 & 47,06 & 45,91 & $43,06 \mathrm{~d}$ \\
12 & 37,42 & 50,00 & 50,19 & $45,87 \mathrm{~d}$ \\
14 & 45,55 & 56,15 & 50,98 & $50,89 \mathrm{c}$ \\
16 & 48,01 & 54,85 & 52,36 & $51,74 \mathrm{c}$ \\
18 & 44,00 & 57,15 & 56,92 & $52,69 \mathrm{bc}$ \\
20 & 49,38 & 62,25 & 59,20 & $56,94 \mathrm{ab}$ \\
22 & 47,38 & 59,85 & 54,50 & $53,91 \mathrm{bc}$ \\
24 & 53,38 & 62,31 & 59,51 & $58,40 \mathrm{a}$ \\
Média & $38,68 \mathrm{C}$ & $48,90 \mathrm{~A}$ & $46,78 \mathrm{~B}$ & \\
\hline
\end{tabular}

$\mathrm{CV} \%=7,08$

${ }^{1}$ Médias seguidas da mesma letra, maiúscula para lotes e minúscula para número de horas de embebição, não diferem significamente ao nível de $5 \%$ de probabilidade pelo teste de Tukey. 
o lote 1 apresentou melhor qualidade fisiológica, pelos testes de germinação, primeira contagem do teste de germinação e pelo teste de condutividade elétrica; todavia para os lotes $2 \mathrm{e}$ 3 , a discriminação nem sempre foi coerente entre os testes.

Entre os períodos de embebição (Tabela 2), os resultados obtidos mostram que quanto maior foi o período de embebição maior o valor da condutividade, ou seja, 24 horas apresentou o maior valor e 2 horas o menor valor, resultados estes coerentes com as observações de Loeffler et al. (1988), Marcos Filho et al. (1990), Dias \& Marcos Filho (1996) e Dias et al. (1998). Verifica-se, entretanto, que nas duas horas iniciais ocorreu uma taxa de lixiviação que possibilita a avaliação da condutividade elétrica da solução de embebição das sementes de milheto e de diferenciação dos lotes. Este resultado confirma Vieira \& Krzyzanowski (1999), quando comentam que em sementes pequenas é possível reduzir o período de embebição para o teste de condutividade elétrica.

A redução do tempo de embebição para o teste de condutividade elétrica foi também conseguida para outras espécies como soja (Marcos Filho et al., 1990; Dias \& Marcos Filho, 1996), girassol (Brandão Jr. et al., 1997), amendoim (Vanzolini \& Nakagawa, 1999b), feijão-de-vagem e quiabo (Dias et al., 1998) e tomate (Rodo et al, 1998; Sá, 1999).

Avaliando-se o grau de umidade das sementes após o teste de condutividade, verifica-se que com o aumento do tempo de embebição houve um aumento no teor de água da semente, acompanhando o modelo trifásico de ganho de água durante o processo de germinação (Figura 1). A partir do período de embebição de 20 horas para os lotes 1 e 2 e a partir de 22 horas para o lote 3, mais de $80 \%$ das sementes já estavam com protusão da raiz primária, o que justificaria o acréscimo do teor de água das sementes a partir desses momentos. O maior ganho de água pelas sementes ocorreu nas duas horas iniciais (Figura 1), à semelhança do observado com os valores de condutividade, indicando maior taxa de lixiviados também nesse período.

\section{Experimento 2 (E2)}

A partir dos resultados da Tabela 3, observa-se que os dois testes de condutividade, sem (E2C1) e com (E2C2) controle de temperatura inicial de embebição, demonstraram a diferença entre os lotes e entre as temperaturas de embebição, mas não houve interação entre os dois fatores, ou seja, não houve influência da tempe- ratura na diferenciação dos lotes no teste de condutividade elétrica para sementes de milheto nas condições estudadas. Para os lotes, observa-se que o Lote 1 foi melhor, seguido pelos Lotes 3 e o Lote 2 o menos vigoroso. Houve aumento da condutividade com o aumento da temperatura de embebição, assim como observado por Loeffler et al. (1988) e Vanzolini \& Nakagawa (1999a). Este efeito tem ocorrido na magnitude do valor da condutividade porém sem alterar a classificação dos lotes (Hampton \& Tekrony, 1995).

Comparando-se as temperaturas (Tabela 3), observa-se que as temperaturas mais altas apresentaram maior valor de condutividade; isso ocorreu porque o aumento na temperatura aumenta a dissociação de íons e reduz a viscosidade da solução, o que resulta em aumento de condutividade (Loeffler et al., 1981). O E2C2 diferenciou melhor as temperaturas de embebição pois as separou estatisticamente em três níveis, sendo as temperaturas de 40 e $35^{\circ} \mathrm{C}$ com os maiores valores de condutividade, seguido por $30^{\circ} \mathrm{C}$ e logo após 25 e $20^{\circ} \mathrm{C}$; enquanto o $\mathrm{E} 1 \mathrm{C} 1$ apenas em dois níveis, tendo as temperaturas de 40 e $35^{\circ} \mathrm{C}$ apresentando os maiores valores de condutividade, seguidas pelas temperaturas de 30,25 e $20^{\circ} \mathrm{C}$ que apresentaram menores valores de condutividade e semelhantes estatisticamente. Essa diferença entre os dois testes deve ser atribuída ao período em que as sementes levaram para atingir a temperatura de embebição estudada, menor em E2C2 e maior em E2C1.

Observando-se os valores de teor de água após a condutividade (Tabela 4), verifica-se que a elevação da temperatura fez aumentar a intensidade de embebição das sementes de milheto e também a lixivia-ção, assim como o ocorrido em tomate (Rodo et al., 1998) e amendoim (Vanzolini \& Naka-

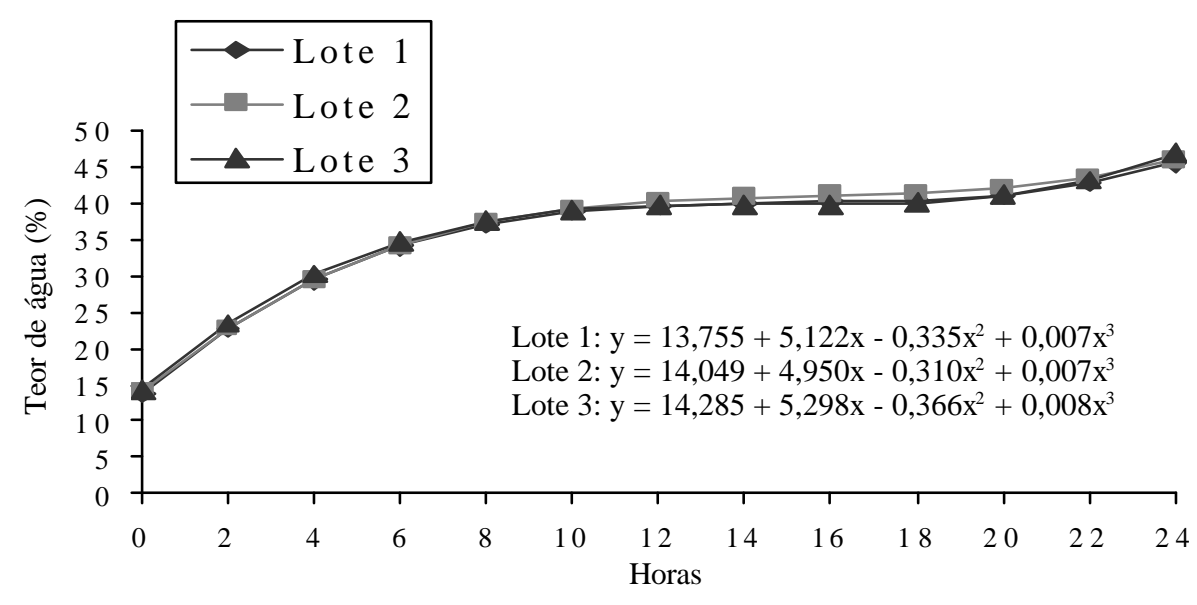

FIG. 1. Curvas estimadas de teor de água após a condutividade de três lotes de sementes de milheto submetidos a diferentes períodos de embebição à temperatura de $25^{\circ} \mathrm{C}$, 
TABELA 3. Dados médios de condutividade elétrica $\left(\mu \mathrm{S} \mathrm{cm}^{-1} \mathrm{~g}^{-1}\right)$, em função de diferentes temperaturas de embebição, sem controle da temperatura inicial da água de embebição (E2C1) e com controle da temperatura inicial da água de embebição (E2C2), para três lotes de sementes de milheto.

\begin{tabular}{ccccccc}
\hline \multirow{2}{*}{ Lotes } & \multicolumn{5}{c}{ Temperaturas } & \multirow{2}{*}{ Média } \\
\cline { 2 - 5 } & $20^{\circ} \mathrm{C}$ & $25^{\circ} \mathrm{C}$ & $30^{\circ} \mathrm{C}$ & $35^{\circ} \mathrm{C}$ & $40^{\circ} \mathrm{C}$ & \\
\cline { 1 - 5 } & \multicolumn{7}{c}{ E...... $2 \mathrm{C} 1$} & - sem controle inicial da temperatura da água de embebição ............. \\
1 & 14,82 & 14,13 & 14,42 & 17,92 & 19,12 & $16,08 \mathrm{C}$ \\
2 & 26,34 & 24,57 & 25,31 & 28,97 & 31,02 & $27,24 \mathrm{~A}$ \\
3 & 21,03 & 20,21 & 22,45 & 23,67 & 24,38 & $22,35 \mathrm{~B}$ \\
Média & $20,73 \mathrm{~b}^{1}$ & $19,63 \mathrm{~b}$ & $20,73 \mathrm{~b}$ & $23,52 \mathrm{a}$ & $24,84 \mathrm{a}$ & \\
$\mathrm{CV} \%=8,21$ & & & & & & \\
\hline
\end{tabular}

E2C2 - com controle inicial da temperatura da água de embebição .....

\begin{tabular}{cllllll}
1 & 19,36 & 17,36 & 26,90 & 30,37 & 33,18 & $25,43 \mathrm{C}$ \\
2 & 30,90 & 30,10 & 35,73 & 40,83 & 42,01 & $35,92 \mathrm{~A}$ \\
3 & 23,45 & 27,18 & 30,87 & 37,95 & 37,04 & $31,30 \mathrm{~B}$ \\
Média & $24,57 \mathrm{c}^{1}$ & $24,88 \mathrm{c}$ & $31,17 \mathrm{~b}$ & $36,38 \mathrm{a}$ & $37,41 \mathrm{a}$ & \\
CV\%=9,00 & & & & & & \\
\hline
\end{tabular}

${ }^{1}$ Médias seguidas da mesma letra, maiúscula para lotes e minúscula para temperatura de embebição, não diferem significamente ao nível de 5\% de probabilidade pelo teste de Tukey.

TABELA 4. Dados médios teor de água (\%) após a condutividade, em função de diferentes temperaturas de embebição, sem controle da temperatura inicial da água de embebição (E2C1) e com controle da temperatura inicial da água de embebição (E2C2), para três lotes de sementes de milheto.

\begin{tabular}{lllllll}
\hline \multirow{3}{*}{ Lotes } & \multicolumn{5}{c}{ Temperaturas } & \multirow{2}{*}{ Média } \\
\cline { 2 - 5 } & $20^{\circ} \mathrm{C}$ & $25^{\circ} \mathrm{C}$ & $30^{\circ} \mathrm{C}$ & $35^{\circ} \mathrm{C}$ & $40^{\circ} \mathrm{C}$ & \\
\hline
\end{tabular}

...E2C1 - sem controle inicial da temperatura da água de embebição......

$\begin{array}{cllllll}1 & 27,6 & 27,5 & 26,9 & 28,8 & 29,8 & 28,1 \mathrm{~B} \\ 2 & 28,1 & 27,8 & 28,6 & 30,4 & 31,1 & 29,2 \mathrm{~A} \\ 3 & 27,1 & 27,8 & 28,4 & 29,7 & 30,1 & 28,6 \mathrm{AB} \\ \text { Médias } & 27,6 \mathrm{~b}^{1} & 27,7 \mathrm{~b} & 28,0 \mathrm{~b} & 29,6 \mathrm{a} & 30,4 \mathrm{a} & \\ \mathrm{CV} \%=1,71 & & & & & & \end{array}$

E2C2 - com controle inicial da temperatura da água de embebição.

\begin{tabular}{cllllll}
1 & $28,1 \mathrm{Ac}$ & $27,4 \mathrm{Bc}$ & $30,6 \mathrm{Ab}$ & $32,4 \mathrm{Aa}$ & $32,5 \mathrm{Aa}$ & 30,2 \\
2 & $27,9 \mathrm{Ad}$ & $29,4 \mathrm{Ac}$ & $30,9 \mathrm{Ab}$ & $33,0 \mathrm{Aa}$ & $32,9 \mathrm{Aa}$ & 30,8 \\
3 & $27,5 \mathrm{Ad}^{1}$ & $28,8 \mathrm{Ac}$ & $30,4 \mathrm{Ab}$ & $32,4 \mathrm{Aa}$ & $32,5 \mathrm{Aa}$ & 30,3 \\
Médias & 27,8 & 28,5 & 30,6 & 32,6 & 32,6 & \\
CV\%=0,51 & & & & & & \\
\hline
\end{tabular}

${ }^{1}$ Médias seguidas da mesma letra, maiúscula para lotes e minúscula para temperatura de embebição, não diferem significamente ao nível de $5 \%$ de probabilidade pelo teste de Tukey. gawa, 1999a).

Comparando E2C1 e E2C2 (Tabela 4), observa-se que o controle da temperatura inicial da água (E2C2) proporcionou maior efeito da temperatura na embebição pois ocasionou quatro níveis com diferença estatística, enquanto o E2C1 apenas dois níveis. O E2C1 propiciou diferença de teor de água entre os lotes, sendo o lote 2 o que apresentou maior teor, seguido pelo lote 3 e pelo lote 1, concordando com Rocha et al. (1984) que observaram, nas sementes de soja, que o lote de qualidade inferior é o que embebia mais. Entretanto o E2C2 não ocasionou diferença de embebição entre os lotes, exceto à temperatura de $25^{\circ} \mathrm{C}$, na qual o lote 1 foi o que apresentou menor embebição. Essa diferença de efeito entre E2C1 e E2C2 no teor de água deve ser devido ao período em que as sementes levaram para atingir as temperaturas estudadas, menor em E2C2 e maior em E2C1. Sabe-se que não só o vigor, mas uma série de fatores externos e internos atuam sobre o processo de absorção de água das sementes e dificilmente consegue-se isolar a interferência individual de cada um deles, devido à possibilidade destes interagirem entre si (Woodstock, 1988).

De acordo com os resultados aqui obtidos, verifica-se que qualquer uma das temperaturas estudadas pode ser utilizada para a realização do teste de condutividade elétrica em sementes de milheto, entretanto o condicionamento a $25^{\circ} \mathrm{C}$ mostra ser uma temperatura mais coerente com as condições ambientais do Laboratório de Análise de Sementes, não só para o Brasil como para países de clima temperado como os Estados Unidos e o Canadá (Vieira \& Krzyzanowski, 1999). Contudo, o uso de temperaturas mais altas como $35^{\circ}$ $\mathrm{C} \mathrm{e} 40^{\circ} \mathrm{C}$ poderia, provavelmente, diminuir ainda mais o período de embebição de duas 
horas ou separar com mais precisão lotes que tivessem vigor próximos. Novos estudos nesse sentido merecem ser feitos para o milheto. Em relação ao controle da temperatura inicial da água, destaca-se que quando se fez uso deste método, como recomendado (Vieira \& Krzyzanowski, 1999), houve melhor diferenciação das temperaturas e seus respectivos valores de condutividade.

\section{CONCLUSÕES}

- A redução do período de embebição das sementes, a $25^{\circ} \mathrm{C}$, de vinte e quatro horas para duas horas possibilita a mesma separação dos lotes de sementes quanto a qualidade fisiológica;

- a temperatura de $25^{\circ} \mathrm{C}$, com período de embebição de duas horas, mostra-se promissora para o teste de condutividade de sementes de milheto.

\section{REFERÊNCIAS}

BRANDÃO JUNIOR, D.S.; RIBEIRO, D.C.A.; BERNADINO FILHO, J.R.; VIEIRA, M.C.C.C. Adequação do teste de condutividade elétrica para determinar a qualidade fisiológica de sementes de girassol. Informativo Abrates, Londrina, v.7, n. 1/2, p. 184, 1997. Trabalho apresentado no X Congresso Brasileiro de Sementes, Foz do Iguaçu, PR, 1997.

BRASIL. Ministério da Agricultura e Reforma Agrária. Regras para análise de sementes. Brasília: SNDA/DNDV/CLV, 1992. 365p.

DIAS, D.C.F.S.; MARCOS FILHO, J. Testes de vigor baseados na permeabilidade das membranas celulares: I. Condutividade elétrica. Informativo Abrates, Londrina, v.5, n.1, p.26-36, 1995.

DIAS, D.C.F.S.; MARCOS FILHO, J. Testes de condutividade elétrica para a avaliação do vigor de sementes de soja. Scientia Agricola, Piracicaba, v.53, nº1, p.31-42, 1996.

DIAS, D.C.F.S.; VIEIRA, A.N.; BHÉRING, M.C. Condutividade elétrica e lixiviação de potássio para avaliação do vigor de sementes de hortaliças: feijão-de-vagem e quiabo. Revista Brasileira de Sementes, Brasília, v.20, n.2, p.408-413, 1998.

GARCIA, D.C.; MENEZES, N.L. de. Teste de envelhecimento precoce para sementes de azevém, aveia preta e milheto. Ciência Rural, Santa Maria, v.29 n.2, p.233-237, 1999.

GASPAR, C.M.; NAKAGAWA, J. Influência do tamanho na germinação e no vigor de sementes de milheto (Pennisetum americanum L. Leeke). In: CONGRESSO DE INICIAÇÃO
CIENTÍFICA DA UNESP, 13., 2001, Bauru. Anais e resumo. Bauru: UNESP, 2001. p.231.

HAMPTON, J.G.; TEKRONY, D.M. Handbook of vigour test methods. 3.ed. Zurich: ISTA, 1995. 117p.

LEOPOLD, A.C. Temperature effects on soybean inibition and leakage. Plant Physiology, Lancaster, v.65, p. 1096-1098, 1980.

LOEFFLER, T.M. The bulk conductivity test as an indicator of soybean seed quality. 1981. 181f. Thesis (Master Science) University of Kentucky, Lexington .

LOEFFLER, T.M.; TEKRONY, D.M.; EGLI, D.B. The bulk conductivity test as an indicator of soybean seed quality. Journal of Seed Technology, Lansing, v.12, n.1, p.37-53, 1988.

MAGUIRE, J.D. Speeds of germination-aid in selection and evaluation for seedling emergence and vigor. Crop Science, Madison, v.2, n.1, p.176-177, 1962.

MARCOS FILHO, J.; CICERO, S.M.; SILVA, W.R. da. Avaliação da qualidade de sementes. Piracicaba: FEALQ, 1987. 230 p.

MARCOS FILHO, J.; SILVA, W.R.; NOVEMBRE, A.C.; CHAMA, H.C.P.C. Estudo comparativo de métodos para avaliação da qualidade fisiológica de sementes de soja, com ênfase ao teste de condutividade elétrica. Pesquisa Agropecuária Brasileira, Brasília, v.25, n.12, p. 1805-1815, 1990.

PIMENTEL-GOMES, F. Curso de estatística experimental. Piracicaba: Escola Superior de Agronomia "Luiz de Queiroz", 1973. 430p.

RIBEIRO, D.M.C.A.; CARVALHO, M.L.M.; SALGADO, K.C.C. Avaliação da qualidade fisiológica de sementes de milho através do teste de condutividade elétrica (bulk). Informativo Abrates, Londrina, v.7, n.1/2, p.187, 1997. Trabalho apre-sentado no X Congresso Brasileiro de Sementes, Foz do Iguaçu, PR, 1997.

ROCHA, V.S.; SEDIYAMA, T.; SILVA, R.F.; SEDIYAMA, C.S.; THIEBAUT, J.T.L. Embebição de água e qualidade fisiológica de sementes de soja. Revista Brasileira de Sementes, Brasília, v.6, n.2, p.51-66, 1984.

RODO, A.B.; TILLMANN, M. A.A.; VILLELA, F. A.; SAMPAIO, N.V. Teste de condutividade elétrica em sementes de tomate. Revista Brasileira de Sementes, Brasília, v.20, n.1, p.29-38, 1998.

SÁ, M.E. Condutividade elétrica em sementes de tomate (Lycopersicon lycopersicum L.). Scientia Agricola, Piracicaba, v.56, n.1, p.13-19, 1999.

SALTON, J.C.; KICHEL, A.N. Milheto: alternativa para cobertura do solo e alimentação animal. Informações Agronômicas, Piracicaba, n.80, p.8-9, 1997.

VANZOLINI, S. Teste de condutividade elétrica em sementes de amendoim (Arachis hypogea L.). 1998. 103f. Dissertação (Mestrado em Agronomia) - Faculdade de Ciências Agronômicas - Universidade Estadual Paulista, Botucatu.

VANZOLINI, S.; NAKAGAWA, J. Teste de condutividade elétrica em sementes de amendoim: efeitos de temperatura e de período de embebição. Revista Brasileira de Sementes, Brasília, v.21, n.1, p.41-45. 1999a.

VANZOLINI, S.; NAKAGAWA, J. Teste de condutividade elétrica em sementes de amendoim: efeitos de teor de água de período de 
embebição. Revista Brasileira de Sementes, Brasília, v.21, n.1, p.46-52. 1999 b.

VIEIRA, R.D.; KRZYZANOWSKI, F.C. Teste de condutividade elétrica. In: KRZYZANOWSKI, F.C.; VIEIRA, R.D.; FRANÇA NETO, J.B. Vigor de sementes: conceitos e testes. Londrina: ABRATES, 1999. p. 1, 4, 26.
VIEIRA, R.D.; PANOBIANCO, M.; LEMOS, L.B.; FORNASIERI FILHO, D. Efeito de genótipos de feijão e de soja sobre os resultados da condutividade elétrica de sementes. Revista Brasileira de Sementes, Brasília, v.18, n.2, p.220-224, 1996.

WOODSTOCK, L.W. Seed imbibition: a critical period for successful germination. Journal of Seed Technology, Lansing, v.12, n.1, p.115,1988 . 